\title{
Inverted Outflow Ground Testing of Cryogenic Propellant Liquid Acquisition Devices
}

\author{
David J. Chato ${ }^{*}$ and Jason W. Hartwig ${ }^{\dagger}$ \\ NASA Glenn Research Center, Cleveland, OH, USA \\ Enrique Rame \\ National Center for Space Exploration Research, Cleveland, OH, USA \\ John B. McQuillen ${ }^{\S}$ \\ NASA Glenn Research Center, Cleveland, OH, USA
}

\begin{abstract}
NASA is currently developing propulsion system concepts for human exploration. These propulsion concepts will require the vapor free acquisition and delivery of the cryogenic propellants stored in the propulsion tanks during periods of microgravity to the exploration vehicles engines. Propellant management devices (PMD's), such as screen channel capillary liquid acquisition devices (LAD's), vanes and sponges have been used for earth storable propellants in the Space Shuttle Orbiter and other spacecraft propulsion systems, but only very limited propellant management capability currently exists for cryogenic propellants. NASA is developing PMD technology as a part of their cryogenic fluid management (CFM) project. System concept studies have looked at the key factors that dictate the size and shape of PMD devices and established screen channel LADs as an important component of PMD design. Modeling validated by normal gravity experiments is examining the behavior of the flow in the LAD channel assemblies (as opposed to only prior testing of screen samples) at the flow rates representative of actual engine service (similar in size to current launch vehicle upper stage engines). Recently testing of rectangular LAD channels has included inverted outflow in liquid oxygen and liquid hydrogen. This paper will report the results of liquid oxygen testing compare and contrast them with the recently published hydrogen results; and identify the sensitivity of these results to flow rate and tank internal pressure.
\end{abstract}

\section{Nomenclature}

$\begin{array}{ll}a & =\text { Surface area to unit volume ratio of screen wire, } \mathrm{ft}^{-1}, \text { constant for a given screen } \\ B & =\text { Screen thickness, } \mathrm{ft} \text {-constant for a given screen } \\ D & =\text { Hydraulic diameter, } \mathrm{ft} \\ d & =\text { Experimentally Determined Pore Diameter, } \mathrm{ft} \\ e & =\text { Acceleration Due to Gravity } \\ g & =\text { Dimension conversion constant, } \mathrm{lb}_{\mathrm{m}}-\mathrm{ft}^{-} \mathrm{lb}_{\mathrm{f}}-\mathrm{sec}^{2} \\ g_{c} & =\text { LAD height below liquid level, } \mathrm{ft} \\ H & =\text { Length of LAD channel that is above the liquid fluid level, } \mathrm{ft} \\ h & =\text { Mass flow rate, lbm/sec } \\ \dot{m} & =\text { Number of channels in LAD }\end{array}$

\footnotetext{
${ }^{* *}$ Lead Aerospace Engineer, Fluids and Cryogenic Systems Branch, 21000 Brookpark Road, MS 301-3, Cleveland, OH 44135, AIAA Associate Fellow.

${ }^{\dagger}$ Research Aerospace Engineer, Fluids and Cryogenic Systems Branch, 21000 Brookpark Road, MS 301-3, Cleveland, OH 44135, AIAA Member.

${ }^{\ddagger}$ c/o NASA Glenn Research Center, 21000 Brookpark Road, MS 110-3, Cleveland, Ohio, 44135, USA, NonMember

${ }^{\S}$ Senior Aerospace Engineer, Fluid and Transport Processes Branch, 21000 Brookpark Road, MS 77-5, Cleveland, Ohio, 44135, USA, Non-Member
} 


$\begin{array}{ll}P & =\text { Pressure } \\ \Delta P_{\text {across screen }} & =\text { Pressure Loss Due to Flow Across Screen } \\ \Delta P_{\text {bubble point }} & =\text { Bubble Point Pressure } \\ \Delta P_{\text {dynamic flow }} & =\text { Pressure Loss Due to the Added Mass Flow } \\ \Delta P_{\text {friction }} & =\text { Pressure Loss Due to Frictional from Flow along Channel } \\ \Delta P_{\text {head }} & =\text { Hydrostatic Pressure } \\ \Delta P_{\text {LAD Channel }} & =\text { Pressure Loss for Flow Through LAD screen and channel } \\ T & =\text { Temperature } \\ W & =\text { LAD width, } \mathrm{ft} \\ V & =\text { Volumetric flow rate, } \mathrm{ft}^{3} / \mathrm{sec} \\ \sigma & =\text { Surface Tension, } \mathrm{lb}_{\mathrm{f}} / \mathrm{ft} \\ \rho & =\text { Liquid Density } \\ \theta_{c} & =\text { Contact Angle }\end{array}$

\section{Background}

$\mathrm{G}^{\mathrm{s}}$ ravity affects many fluidic processes, such as the separation of liquid and vapor within a tank: the liquid (heavier fluid) settles to the bottom while the vapor (lighter fluid) rises to the top. In the reduced gravity of a space environment, surface tension becomes a controlling mechanism for this liquid/vapor separation in a tank as the liquid and vapor tend to the state of lowest potential energy. For "wetting" systems, the liquid tends to wrap the walls or interior structures within the tank often resulting in no or very little vapor contact with the walls and these structures.

When transferring propellant in space, it is necessary to transfer single phase liquid from a propellant tank to an engine to ensure efficient thermal conditioning of the engine and safe operation after ignition. In Earth's gravity field or under acceleration during "significant" thrusting such as a main engine firing, propellant transfer is fairly simple. Single-phase fluid is transferred by opening a valve at the bottom of the propellant tank and installing an anti-vortex baffle over the tank outlet to prevent vapor and gas ingestion into the outlet. In low gravity where fluid does not sufficiently cover the tank outlet, withdrawing single-phase fluid becomes a challenge. Unsettled pressure control is also a challenge due to the risk of ingesting pressurant in the outflow line. A variety of propellant management devices (PMD) are required to ensure single-phase flow, depending on the gravitational environment. One type of PMD, a liquid acquisition device (LAD) uses capillary flow and surface tension for acquiring liquid. Capillary flow LADs have been well characterized for storable propellants (propellants that are liquids at room temperature) for in-space propulsion needs. System trades over a number of years have shown the usefulness LADs even for cryogenic applications, Wollen et al. ${ }^{1}$ provides a good summary of these trades.

LADs are designed and manufactured in a variety of sizes and geometries. Multiple types of LADs are often required to achieve sufficient vapor free liquid. One type of LAD is a screen channel device. Screen channel devices closely follow the contour of the propellant tank wall and can vary in cross-section (typically a triangular or rectangular cross section). The channel side that faces the tank wall has multiple openings that are covered with tightly woven screen. As liquid is withdrawn from the tank, surface tension forces within the screen weave create a barrier to vapor entrance into the channel but allow liquid to flow freely. Liquid is wicked into the screen pores and prevents the screen from drying out if it comes into contact with vapor. If the screen dries out, vapor is admitted to the channel.

One purpose of these tests is to gain an understanding of pressure drop across a screen channel LAD during propellant outflow under a variety of conditions. These conditions range from a main engine burn to a small thruster firing or fluid circulation for the thermodynamic vent system. During a main engine burn, the thrust generated will generate a significant acceleration that will settle the propellant over the tank outlet. The LAD must not generate a large pressure loss at these over a pound a second flow rates. A significant pressure loss could result in cavitation, either from dissolved gas pressurant in the liquid propellant or from vaporization of the liquid propellant. More critical though is that the engine designers expect a minimum delivery pressure to ensure reliable and efficient engine operation. 
The second purpose is to determine the bubble break-through pressure under flow conditions. As can be seen in Figure 1, there are multiple contributors to pressure losses in the system including pressure drop across the screen, frictional and dynamic (velocity) pressure losses due to flow along the channel, and head pressure losses. That is

$$
\Delta P_{\text {bubble point }}>\Delta P_{\text {head }}+\Delta P_{\text {across screen }}+\Delta P_{\text {friction }}+\Delta P_{\text {dynamic flow }}
$$

Prior LAD work has produced functional relationships for all these factors (see Hartwig et $\mathrm{al}^{2}$ for a detailed explanation). The geometry of the pore and the fluid surface tension determine the bubble point of the screen. "Bubble point" is defined as the differential pressure across the screen that overcomes the surface tension of the liquid on the screen. Mathematically ${ }^{3}$, bubble point is expressed as:

$$
\Delta P_{\text {bubble point }}=\frac{4 \sigma \cos \theta_{c}}{d}
$$

For liquid oxygen on stainless steel the contact angle is practically zero so the cosine term is one. A high bubble point (fine screen mesh) is desirable to ensure single phase (liquid) fluid delivery and good wicking of fluid into the screen pores. Fine mesh screens, however, tend to generate a large pressure loss during outflow through the screen. The total pressure loss in the system must be less than the bubble point pressure to prevent vapor ingestion into a LAD channel.

For hazardous storable propellants, such as nitrous tetroxide and monomethyl hydrazine (MMH), bubble points are typically determined experimentally using isopropyl alcohol (IPA). However, safety and environmental concerns over the use of storable propellants have led to the examination of non-toxic cryogenic propellants for on-orbit propulsion for the human and robotic exploration of the Moon and Mars. Developing LAD technology for cryogenic propulsion systems and depots is enabling technology for the efficient transfer of cryogenic fluids in a low gravity environment. The use of cryogenic fluids in on-orbit propulsion systems offers the advantages of higher performance. The development of the technology must be capable of providing vapor free liquid despite the continuously changing conditions in a cryogenic propellant tank including pressurization gasses, liquid saturation conditions, vapor entrapment within the tank internal structure, tank pressure control/venting, and heat transfer. Prior work in liquid oxygen has included extensive bubble point testing of the screen material ${ }^{3,4,5}$ as well as outflow testing at lower flow rates and pressures ${ }^{6}$

\section{Cryogenic Fluid Management Liquid Supply Task Description}

As a part of NASA's cryogenic fluid management development, NASA is investigating technologies to provide thermally efficient delivery of a single phase fluid to the systems requiring cryogens. The project team is undertaking development and test of liquid acquisition devices, including settling and outflow, analysis of data on performance of screen channels, and helium pressurization validation studies. The current research effort is focused on screen channel Liquid Acquisition Devices vapor-free liquids for on-orbit propulsion systems, at flow rates necessary for Main Engine Systems (over a pound per second), Reaction Control Systems (up to a pound a second), and Thermodynamic Vent Systems (often much less than a pound an hour, although mixing flows are closer to RCS levels). The high flow rate liquid oxygen LAD tests were prepared to characterize the LAD screen properties, and minimizing propellant tank residuals.

\section{High Flow Rate LAD Test Objectives}

The objective of the high flow rate LAD test was to provide exploratory benchmark data for representative flow conditions of LOX through a prototypical LAD channel. Representative flow conditions include expected flow rate, pressure and temperature of LOX as close as possible to the usage conditions predicted by mission studies ${ }^{7}$ yet were still within capabilities of the test facility. Three major test series were planned: a pressure drop through screen to measure the pressure loss across the screen material itself

$\Delta P_{\text {across screen }}$; a horizontal LAD outflow to determine the flow loss down the channel $\Delta P_{\text {friction }}+\Delta P_{\text {dynamic flow }}$; and a vertical LAD

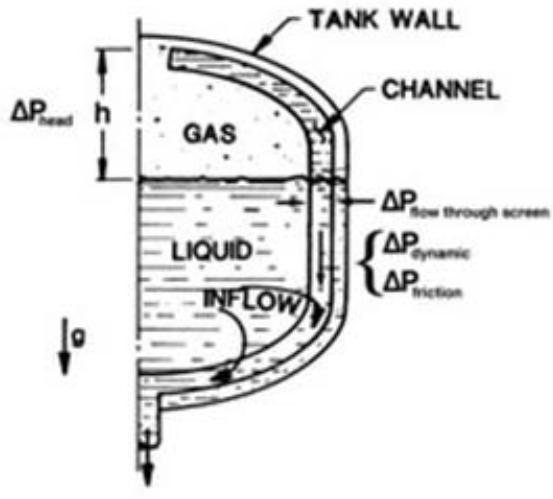

Figure 1: Pressure Drop Contributions 
inverted outflow to measure the actual bubble point itself under flow conditions. This data will be used to develop and refine predictive models for LAD design. Results of the pressure drop and horizontal outflow testing have been reported previously in Hartwig'. This report will focus on the vertical outflow testing.

\section{Description of Experimental Setup}

The experiment was conducted in the 6 foot diameter by 10 foot tall Small Multipurpose Research Facility (SMiRF) vacuum chamber at the NASA Glenn Creek Road Cryogenic Facility ${ }^{8}$. The vacuum chamber provides the insulation necessary to conduct cryogenic testing without having to vacuum jacket complex test hardware, and is designed and equipped to conduct research with reactive cryogens safely.

\section{A. Research LADs}

For each of the desired tests a custom liquid acquisition device was prepared. The design of these was to capture the key flow characteristics of the flight LADs although not necessarily the weight and exact geometry of a flight system.

For the two vertical LADs, a rectangular 2" wide by 1" deep by 24" long channel was sealed with a metal frame containing an opening 2" wide by 19" long covered with fine mesh screen (325 warp and 2300 weft wires per inch in a tight Dutch twill weave, see Hartwig et $\mathrm{al}^{2}$ for more details) which served as a "window" to allow flow. The two vertical LADs, designated LADs 3 and 4, were identical with the exception that LAD 3 had its screen window welded in place with a series of overlapping spot welds rather than the diffusion bond used to attach the screen window for the rest of the LAD channels. The diffusion bonding technique used manufacture LAD 4 was significantly more challenging than the spot welding used for LAD 3. LAD 3 replaced a LAD whose screen had disintegrated during diffusion bonding. Even so the spot welding of LAD 3 required several reworks before an acceptable seal was obtained. One inch diameter outlet tubes were welded to the back of either end of the channel, and tubes for pressure taps installed at four locations along the back of the channel. Although two outlet tubes were provided to allow for flushing through the LAD assembly, only one outlet was used in test, and the other capped. In addition the two middle pressure taps were also capped, because at the flow rates planned for this test it was felt that little pressure signal could be obtained. Figure 2 shows a concept of this LAD in operation.

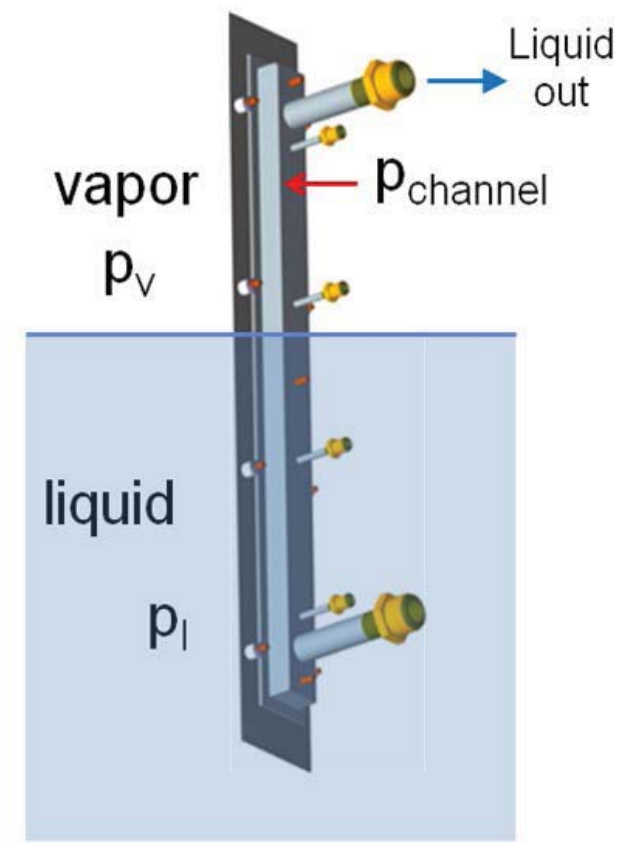

Figure 2 Vertical LAD

In addition to the LAD for the vertical outflow test, it was necessary to design a sight glass so that when gas broke through the screen the gas bubbles could be observed directly. It was decided to place the sight glass within the test tank itself so that if the sight glass leaked or cracked the liquid oxygen would be contained within the tank itself 
rather than leaking into the SMiRF vacuum chamber. An existing viewport for the test tank allowed the camera to reside outside the test tank, both minimizing heat leak into the tank, and isolating the camera from the cold and chemically reactive environment of liquid oxygen. A fiber optic light source available from previous testing was also used. The sight glasses themselves had to be custom designed, not only to withstand the liquid oxygen environment, but also in case of emergency the full 250 psi maximum design pressure of the test tank as well. The sight glasses are designed with a 6" long by 1" square flow channel for flow with quartz glass forming the top and bottom of the channel. Although the square channel does induce some flow disturbance from the 0.870 " I.D. tube, the flat glass offers a significantly reduced optical distortion compared to the curved surface required to match the tube. To save space and material, a design incorporating sight glasses for both vertical LADs in one assembly was used. A white Teflon sheet was mounted behind the sight glass assembly to diffuse the light from the fiber optic light source. Figure 3 shows the sight glass.

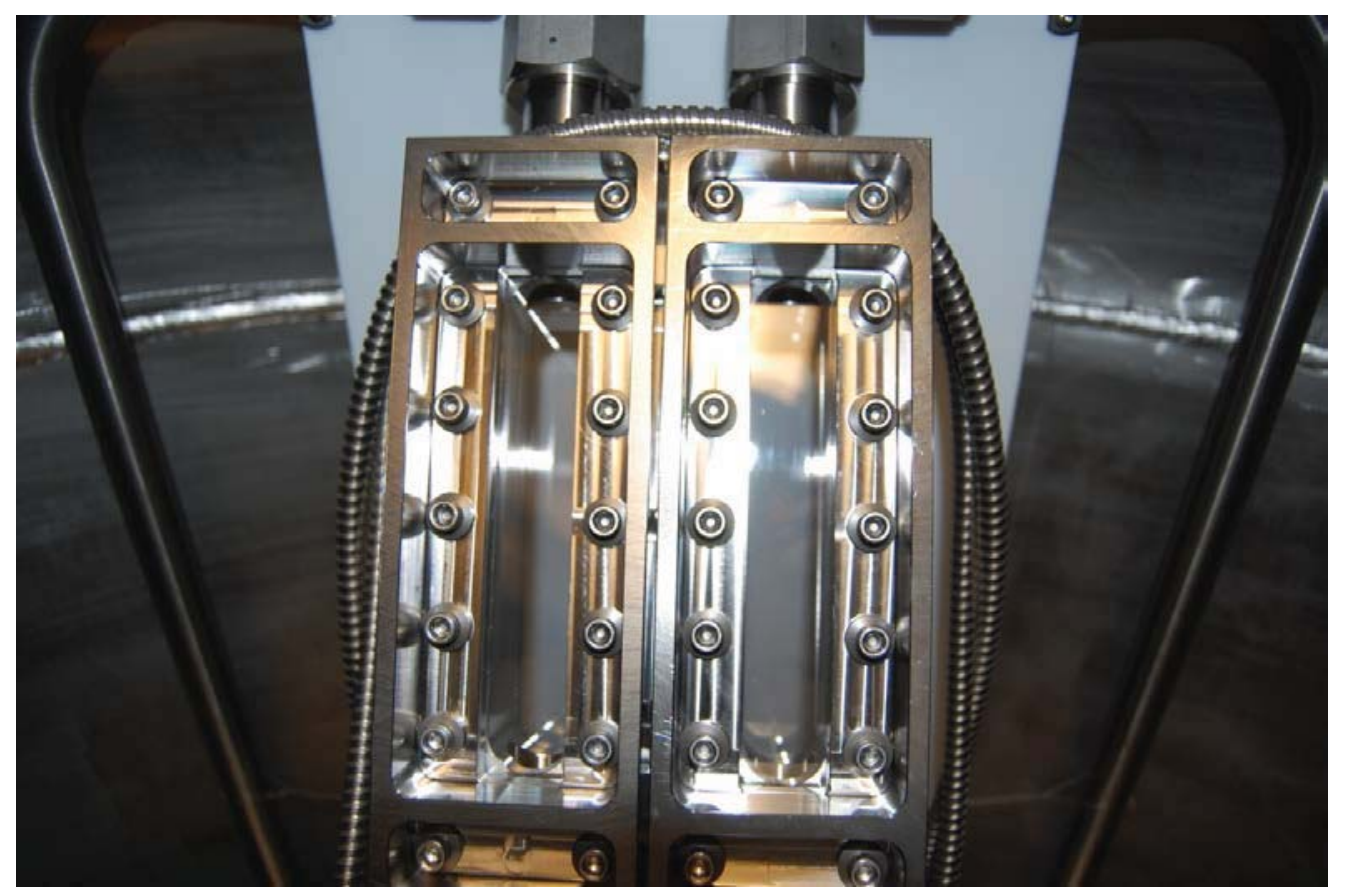

Figure 3 Sight Glass Hardware being installed in Tank

\section{B. Test Tank}

An existing liquid oxygen tank rated for test pressures up to 250 psia was used. The tank is cylindrical with elliptical heads and a cylindrical neck at the top. The diameter of the tank is 48in. The overall length is approximately 75 in and volume is approximately $58 \mathrm{ft}^{3}$. An accurate load cell weighing system was used to determine the quantity of fluid in the test tank. Transducers provide measurements of tank pressure from $0-300 \mathrm{psia} \pm 0.073 \%$ of full scale and from $0-100 \mathrm{psia} \pm 0.1 \%$ of full scale. Thermocouples measured the tank wall, line and tank support temperatures within $\pm 1 \mathrm{R}$. Inside the tank silicon diodes act as both temperature sensors and point liquid level sensors. They had accuracies of $\pm 0.45 \mathrm{R}$ below $180 \mathrm{R}$, and $\pm 0.9 \mathrm{R}$ at temperatures above $180 \mathrm{R}$. A room temperature gaseous helium supply (consisting of a trailer of high pressure gas cylinders and an electronically adjustable pressure regulation system) was used to ramp up from atmospheric pressure to the test pressure and maintain pressure within \pm 3 psia during liquid expulsion. Figure 4 shows a solid model CAD layout of the vertical LADs and sight glass within the tank. Figure 5 shows the interior of the test tank with the test hardware installed (view from the top neck of the tank looking straight down into the interior). Figure 6 shows the test tank as it is lowered into to the SMiRF chamber. 


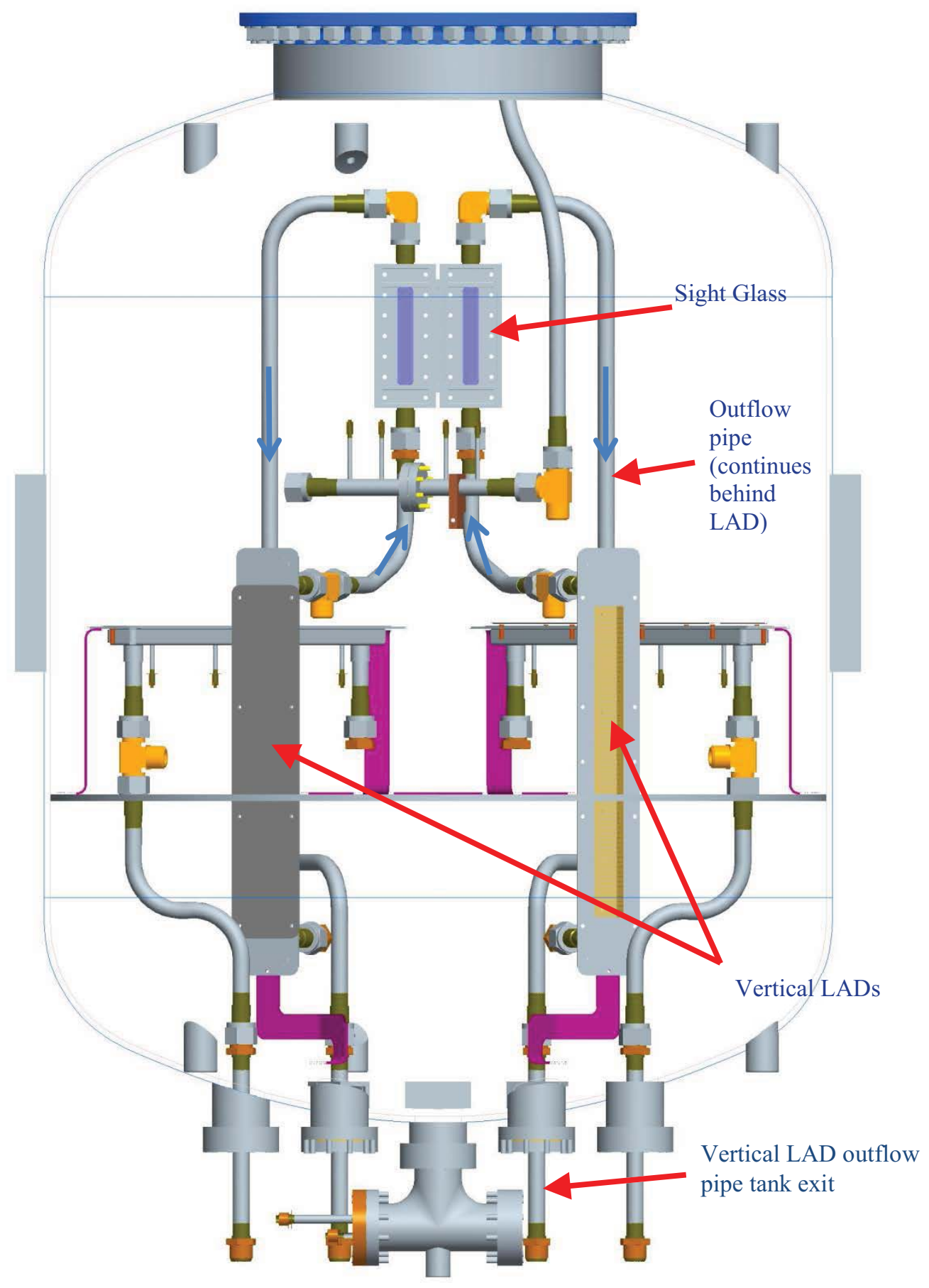

Figure 4: Test Layout within SMiRF Tank 


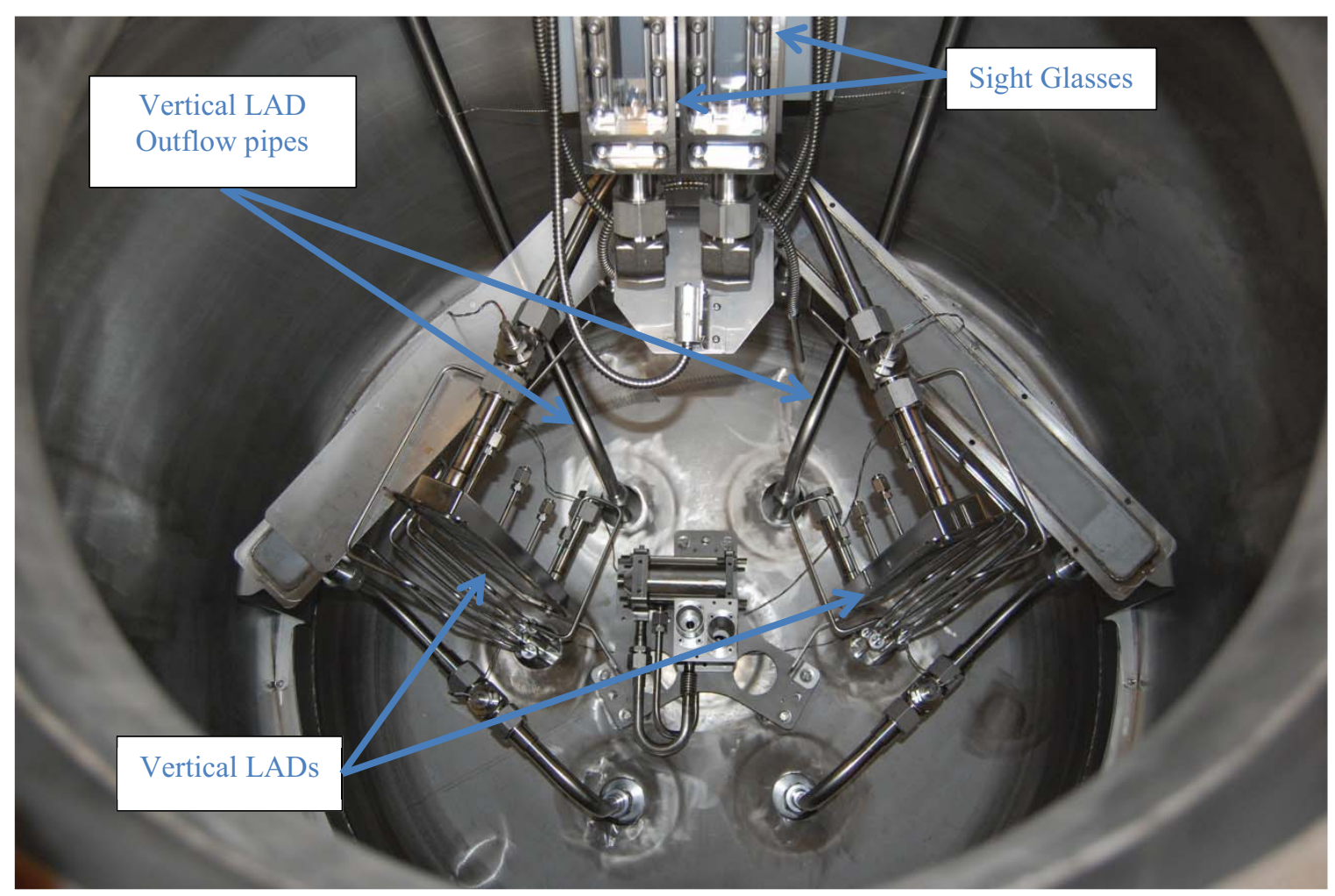

Figure 5 Test Hardware Installed in Tank

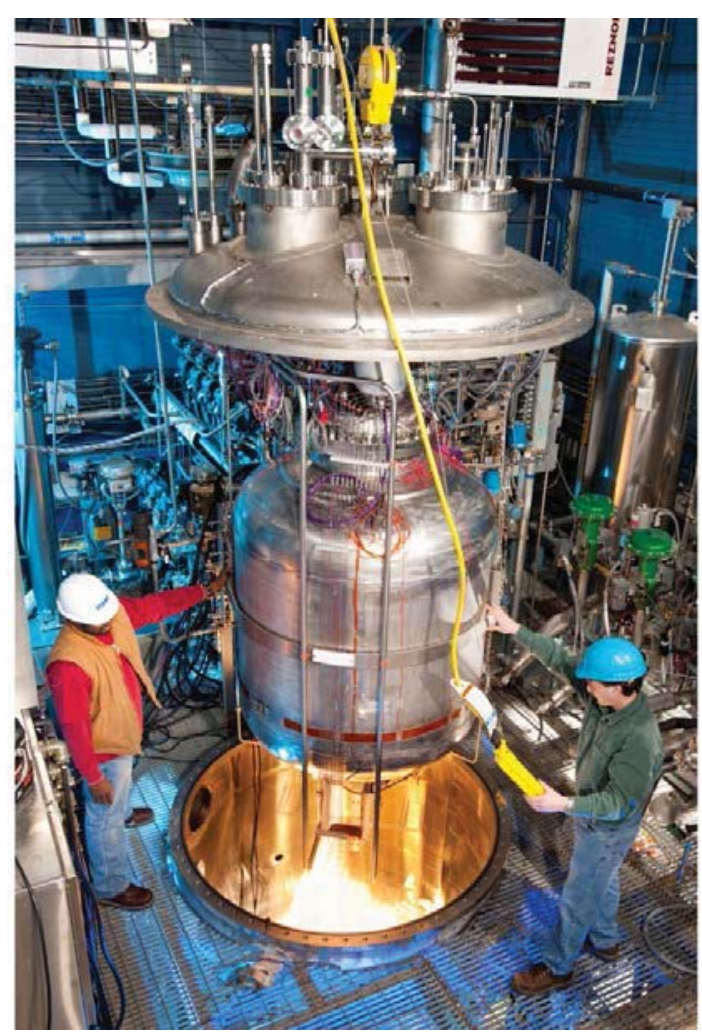

Figure 6 Test tank being lowered into SMiRF chamber 


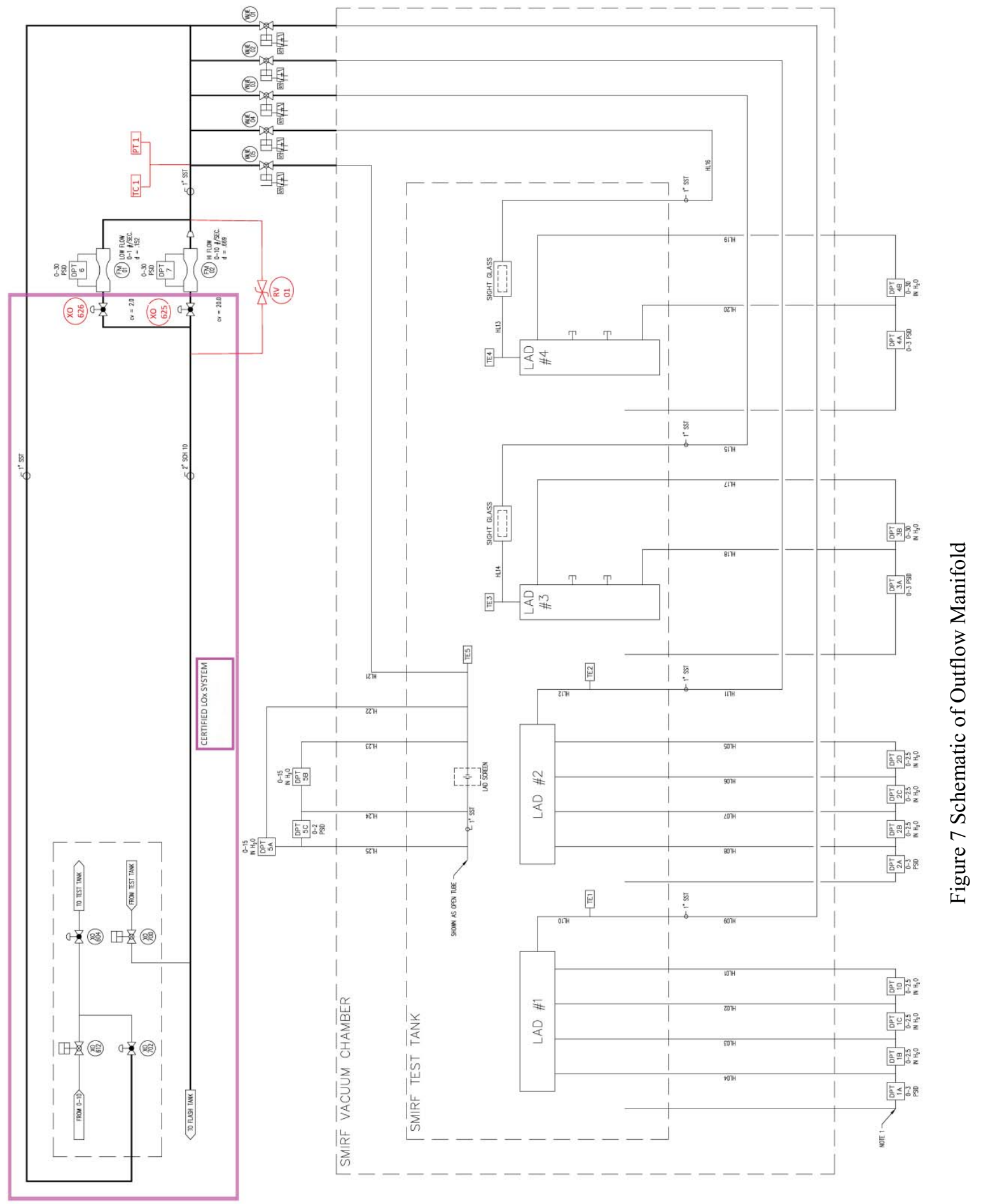




\section{Outflow Manifold}

To accommodate the flow rates of LOX required for these tests, a new outflow manifold was added to the facility. A series of on-off valves selected the test LADs and routed the outflow to a flow control valve and venturi flow meter in either a high or low flow leg. LOX from the manifold was routed to a flash tank located immediately outside the test building. Figure 7 shows a schematic of this system.

\section{Data Requirements}

Data for this test program was acquired using the facility data collections system. It is a computer based system capable of recording up to 380 channels of data at $1 \mathrm{~Hz}$. The most critical measurements for these tests were differential pressure, LOX temperature and visual observation.

\section{E. Experimental Procedure}

Each of the LADs was tested at three pressures $(50,150$, and 250 psia) and three bulk liquid temperatures $(162,173$ and $190^{\circ} \mathrm{R}$ ). In order to accommodate as many test points in a time efficient manner as possible, the tank was filled, warmed and pressurized before testing was initiated. The tank was then drained by first performing a horizontal outflow test, then a pressure drop test, and finally the vertical LAD outflow bubble breakthrough tests (which are the subject of this report). The test hardware was arranged such that sufficient liquid was available to maintain a flow into each piece of test hardware. Tests were run sequentially without having to depressurize, refill and recondition the LOX.

\section{Results}

Pressure data for the vertical LADs records only the pressure drop along the entire length of the channel and the absolute pressure at the bottom of the channel. Unfortunately the signal-to-noise of pressure drop data in these tests is quite poor, typically showing no variation in $\Delta P$ with $\dot{m}$. In addition to pressure, video of the outflow was recorded through a view port downstream of the channel. This video allows one to determine when vapor has broken through the screen, and to correlate the breakthrough with liquid level in the tank, length of screen uncovered (i.e. exposed to vapor), ullage temperature, etc. Table 1 shows the bubble breakthrough test data sorted by LAD then temperature. Two runs which showed bubbles in the line before the LAD was uncovered were discarded. The points of first and all bubble occurrences were picked out of video recordings which were synchronized with the data acquisition clock. From this, the tank fill level can be known for the first bubble and all-bubble conditions, and a linear calibration is used to relate tank fill to fraction of screen uncovered by liquid. Although screen performance is often measured by "Bubble Point" pressure, for these tests, an accurate calculation would require temperatures at the screen surface and throughout the flowing liquid column as well. Data is instead correlated by uncovered length, which is related to "Bubble Point", without needing a temperature distribution to calculate. Longer uncovered screen lengths are indicative of higher "Bubble Points". Figs. 8, 9 and 10 show correlations of uncovered screen length versus $T, P$, and $\dot{m}$, at the time the first tiny bubbles were seen through the view glass. Figure 8 includes a theoretical prediction for the uncovered screen height based on the pore size estimated for $325 \times 2300$ screen of 0.000567 inches given in Hartwig, McQuillen and Jurns ${ }^{5}$, and the assumption that the liquid density and surface tension values are at the bulk liquid temperature. In general the test data in figure 8 shows the same trend of decreasing screen length with temperature. The same trend of temperature and exposed screen was observed during LH2 testing ${ }^{9}$. However the uncovered screen lengths for the test data are notably further from theoretical values than LH2, and show some significant scatter at the lower temperatures, particularly for LAD 4. For figure 9 a different theoretical prediction is shown which assumes the fluid properties of density and surface tension are the same as saturated liquid at the current tank pressure. Although this curve is closer to the test data at the lower pressures, it undershoots the data at the highest pressure. This indicates that subcooling of liquid within the LAD is a significant influence at this pressure. Although it has been speculated that, when the flow rate increases, pressure drop across the screen and along the channel both increase; leading to an earlier breakdown, there is too much scatter in the data presented in figure 10 to conclude this. 


\begin{tabular}{|c|c|c|c|c|c|c|}
\hline Date & $\begin{array}{c}P \\
\text { (psia) }\end{array}$ & $T(R)$ & $\begin{array}{l}\text { LAD } \\
\text { No. }\end{array}$ & $\begin{array}{l}\text { Uncovered } \\
\text { Screen } \\
\text { Length } \\
\text { 1st Bubble } \\
\text { (in) }\end{array}$ & $\begin{array}{l}\text { Uncovered } \\
\text { Screen } \\
\text { Length } \\
\text { All Bubble } \\
\text { (in) }\end{array}$ & $\begin{array}{c}\text { Flow rate(s) } \\
(\mathrm{lb} / \mathrm{s})\end{array}$ \\
\hline $\begin{array}{l}\text { Feb. } \\
24\end{array}$ & 50 & 163 & 3 & 5.96 & 6.16 & 0.3 \\
\hline $\begin{array}{l}\text { Mar. } \\
12\end{array}$ & 50 & 163 & 3 & 9.05 & 9.08 & 0.2 \\
\hline Mar. 5 & 150 & 163 & 3 & 5.83 & 6.28 & 0.3 \\
\hline Mar. 5 & 150 & 163 & 3 & 5.61 & $\begin{array}{c}\text { not } \\
\text { observed }\end{array}$ & 0.3 \\
\hline $\begin{array}{l}\text { Feb. } \\
26\end{array}$ & 240 & 163 & 3 & 5.76 & 6.21 & 0.3 \\
\hline $\begin{array}{l}\text { Mar. } \\
11\end{array}$ & 240 & 163 & 3 & 6.56 & 6.82 & 0.2 \\
\hline $\begin{array}{l}\text { Mar. } \\
16\end{array}$ & 240 & 163 & 3 & 8.39 & 8.53 & 0.4 \\
\hline Mar. 2 & 50 & 173 & 3 & 8.53 & $\begin{array}{c}\text { not } \\
\text { observed }\end{array}$ & 0.3 \\
\hline $\begin{array}{l}\text { Mar. } \\
11\end{array}$ & 240 & 195 & 3 & 4.41 & 6.06 & 0.3 \\
\hline $\begin{array}{l}\text { Feb. } \\
24\end{array}$ & 50 & 163 & 4 & 4.24 & 4.55 & 0.3 \\
\hline & 150 & 163 & 4 & 0.73 & 2.00 & 0.3 \\
\hline $\begin{array}{l}\text { Feb. } \\
26\end{array}$ & 240 & 163 & 4 & 2.60 & 2.86 & 0.3 \\
\hline $\begin{array}{l}\text { Mar. } \\
16 \\
\end{array}$ & 240 & 163 & 4 & 6.72 & 7.39 & 0.4 \\
\hline $\begin{array}{l}\text { Mar. } \\
17\end{array}$ & 240 & 163 & 4 & 8.59 & 9.97 & 0.2 \\
\hline Mar. 3 & 50 & 173 & 4 & 5.06 & 6.72 & 0.3 \\
\hline $\begin{array}{l}\text { Mar. } \\
18 \\
\end{array}$ & 240 & 175 & 4 & 7.10 & $\begin{array}{c}\text { not } \\
\text { observed }\end{array}$ & 0.3 \\
\hline $\begin{array}{l}\text { Mar. } \\
17\end{array}$ & 240 & 193 & 4 & 5.79 & 6.19 & 0.3 \\
\hline
\end{tabular}

Table 1: Summary table of vertical LADs tests. 


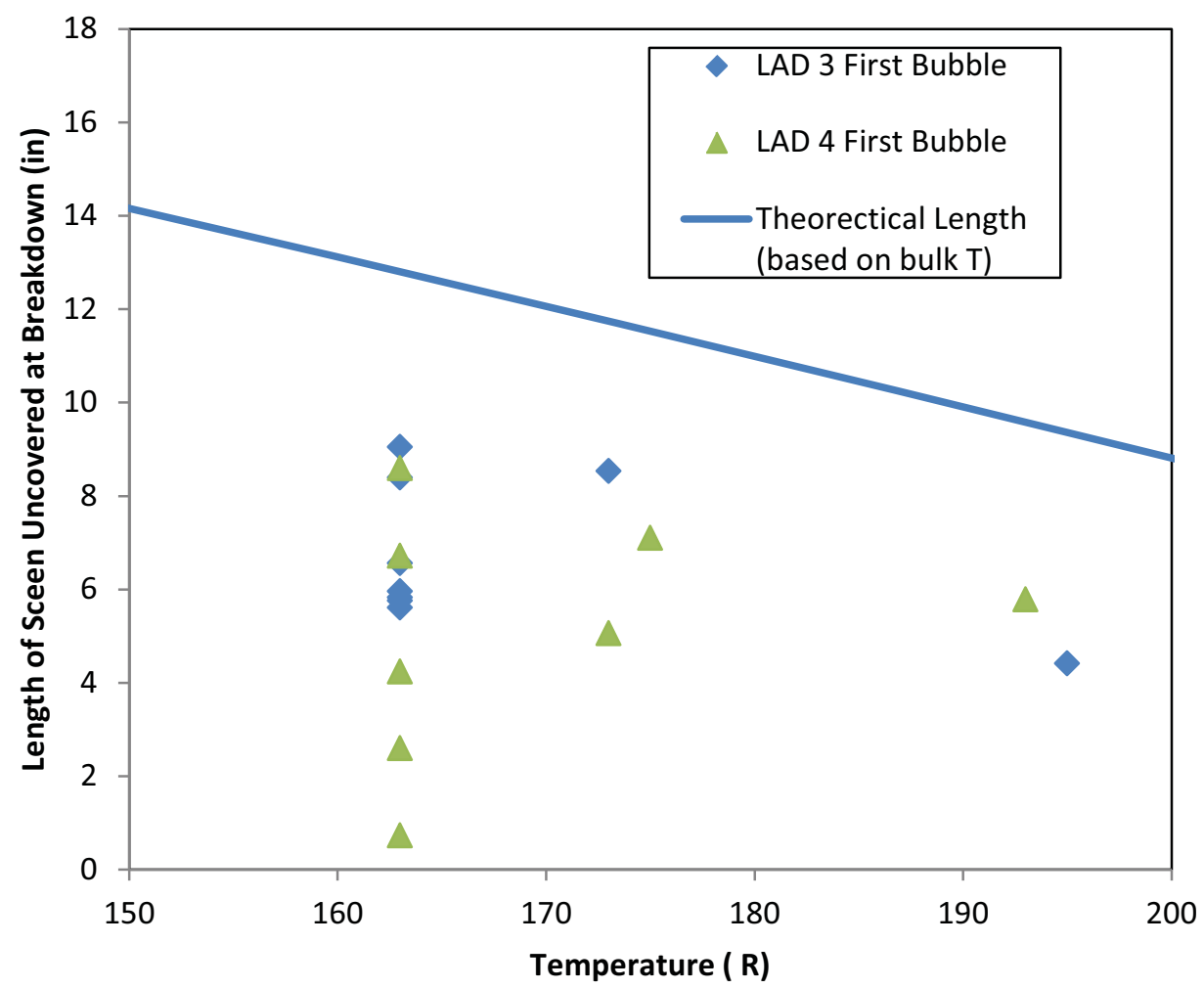

Figure 8: Vertical LADs. Length of screen uncovered at first bubble versus temperature.

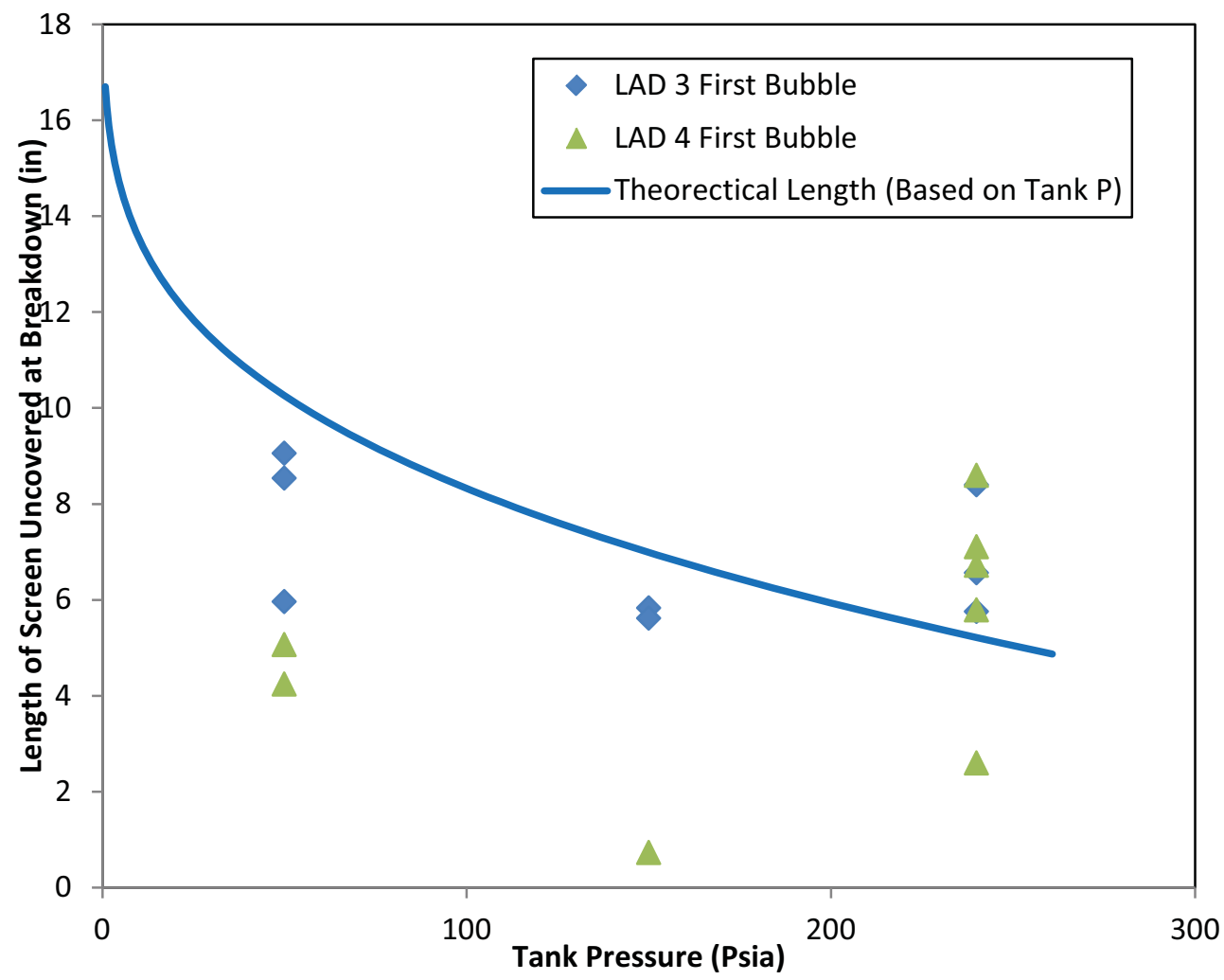

Figure 9: Vertical LADs. Length of screen uncovered at first bubble versus pressure. 


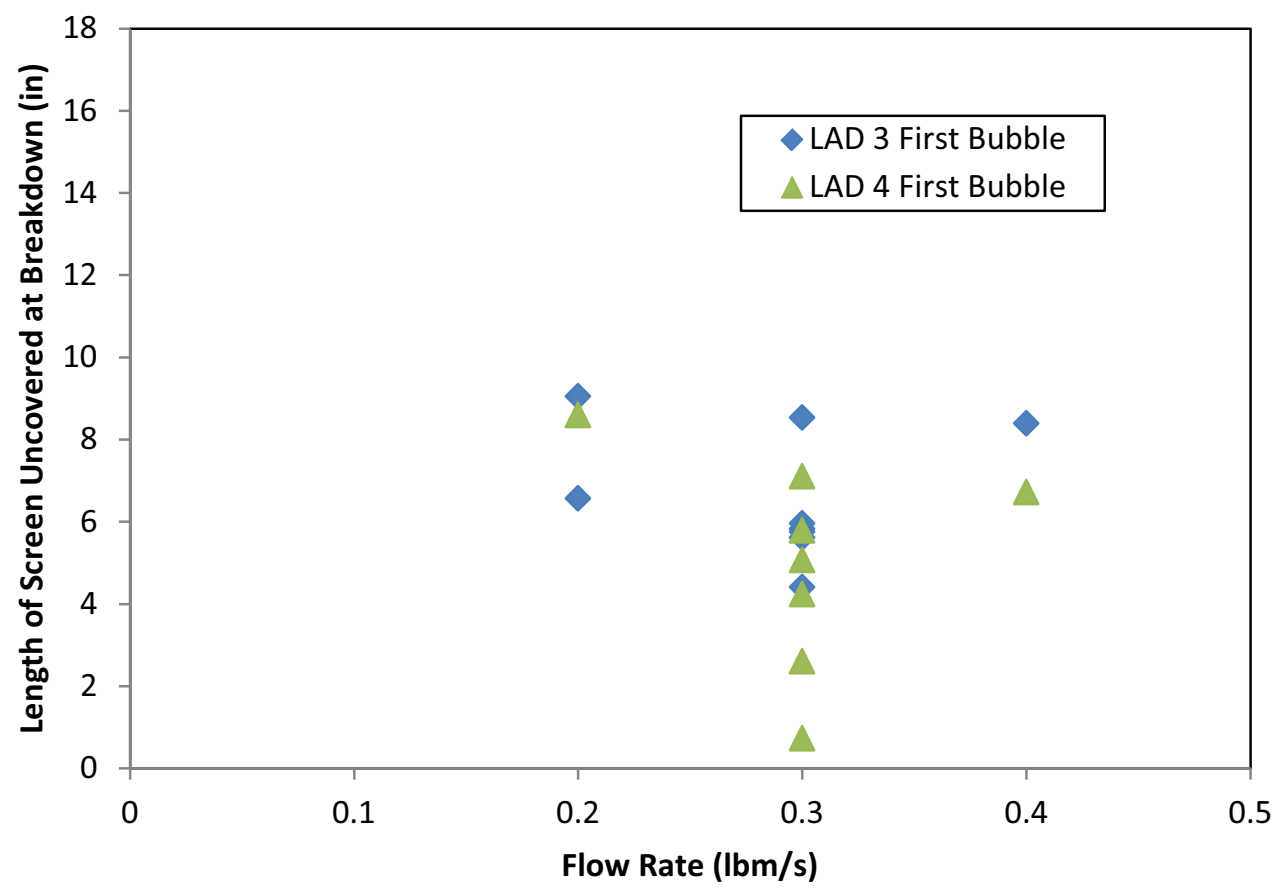

Figure 10: Vertical LADs. Length of screen uncovered at first bubble versus mass flow rate

\section{Concluding Remarks}

Work on the high LAD outflow test has generated both successes and challenges. It has demonstrated an ability to acquire liquid oxygen and maintain a substantial flow rate without causing LAD breakdown. It has shown an ability to do this over a wide range of pressures and temperatures, while determining the screen breakdown by visual observation of bubbles in the sight glass. The initial breakdown is followed quite closely by a screen-wide breakdown in most tests, showing no unusually weak spots in either LAD. No degradation in performance was found with time, in fact some of the highest uncovered screen lengths were observed in some of the last tests. It proved challenging to obtain a consistent measurement of uncovered screen lengths during the tests. Although LAD 3 seemed to slightly outperform LAD 4, the results were not conclusive.

\section{References}

1. Wollen, Mark; Merino, Fred; Schuster, John; Newton, Christopher "Cryogenic Propellant Management Device: Conceptual Design Study" NASA/CR-2010-216777.

2. Hartwig, J.W., Darr, S.R., McQuillen, J.B., Rame, E., and Chato, D.J. “A Steady State Pressure Drop Model for Screen Channel Liquid Acquisition Devices" Cryogenics (accepted for publication). 2014.

3. Jurns, J.M. and Hartwig, J.W. "Liquid Oxygen Liquid Acquisition Device Bubble Point Tests with High Pressure LOX at Elevated Temperature" Space Cryogenic Workshop June 8 - 10, 2011, Coeur d'Alene, Idaho.

4. Jurns, J.M. and McQuillen, J.B., "Liquid Acquisition Device Testing with Sub-cooled Liquid Oxygen" AIAA-2008-4943 44th Joint Propulsion Conference and Exhibit, Hartford, CT, July 21 - 23, 2008.

5. Hartwig, J.W., McQuillen, J.B., and Jurns, J.M. "Screen Channel LAD Bubble Point Tests in Liquid Oxygen" Journal of Thermophysics and Heat Transfer (in press). 2014.

6. Kudlac, M.T. and Jurns, J.M, "Screen Channel Liquid Acquisition Devices for Liquid Oxygen,” AIAA2006-5054, 42 ${ }^{\text {nd }}$ Joint Propulsion Conference, Sacramento, CA, July $9-12,2006$.

7. "Exploration Systems Architecture Study Final Report" NASA/TM-2005-214062.

8. Jurns, J. M. and Kudlac, M. T. "NASA Glenn Research Center Creek Road Complex-Cryogenic Testing Facilities" Cryogenics Volume 46, Issues 2-3, February-March 2006, Pages 98-104

9. Hartwig, J.W., Chato, D.J., McQuillen, J.B., Vera, J., Kudlac, M.T., and Quinn, F.D. "Screen Channel Liquid Acquisition Device Outflow Tests in Liquid Hydrogen" Cryogenics (accepted for publication). 2014. 